\title{
The unanticipated performance of a weak massive rock mass at depth and the added value of observational engineering
}

\author{
KS Kalenchuk Mine Design Engineering, Canada \\ CD Hume Mine Design Engineering, Canada \\ F Morin Fresnillo Plc., Mexico \\ WF Bawden Mine Design Engineering, Canada \\ J Oke Mine Design Engineering, Canada \\ CK Palleske Mine Design Engineering, Canada
}

\begin{abstract}
A site investigation for the Fresnillo shaft expansion program revealed that mylonitic shale, characterised as massive but weak, would be encountered near the planned shaft bottom and in the vicinity of large excavations required for the proposed crusher station and ore handling infrastructure. The rock mass is sparsely jointed, however, fails readily along graphitic planes of weakness in the mylonitic fabric. At roughly $950 \mathrm{~m}$ depth, excavations within this weak rock mass were expected to squeeze and excavation support was designed accordingly. The mylonitic shale was encountered within a ramp in a nearby region of the mine prior to shaft sinking and was observed to stand-up well with minimal ground support at $790 \mathrm{~m}$ below surface. This paper demonstrates the value of observational engineering where observed ground behaviour was back-analysed to improve the site geomechanical model, thus, providing an opportunity for design optimisation and risk mitigation for a major shaft expansion project.
\end{abstract}

Keywords: observation engineering, very weak and massive rock mass

\section{Introduction}

Knowledge and understanding of the geomechanical behaviour of rock masses encountered, or expected to be encountered, during mining is essential to a strategic and optimised mine design. Geotechnical data are the foundation to the geomechanical models used for planning extraction strategies, defining ground support designs, siting permanent infrastructure and determining blasting requirements, among many others aspects of mine design and operations. Early in mine life, as an operation transitions from feasibility design into construction, there is generally some data (of varying quantity and quality) available to quantify intact and rock mass properties, however, at this stage there is rarely data available to predict with certainty the rock mass behavioural response to mining activity.

Conceptually, engineering design is a sequential process where data collection precedes analysis and design. However, this design concept is not necessarily appropriate, or applicable for deep mining projects. A more applicable design process is a continuous process where several of the steps are either run in parallel or through several iterations (observations are made to continually update designs), (Hadjigeorgiou 2012). A continuous and iterative design process is necessary in mining geomechanics where problems are nearly always considered data-limited; any actual data collected from samples are only a very small fraction of the field scale rock mass (Bawden 2015). Preliminary designs (scoping, feasibility, early mine life) are typically based on empirical or numerical assessment, and empirical relationships are used to supplement the necessary parameters required. Geomechanical information always falls within the data-limited category (Holling 1978), however, the uncertainty associated with this data limitation can be mitigated by the continuous process of refining the geomechanical model with relevant information (new intact rock and rock 
mass data, instrumentation and monitoring data, visual observations, calibrated models) as the project moves from construction to operation. The geomechanical database must evolve as the mining operation progresses, in order to validate and optimise the design decisions and assumptions made earlier in the process (Brady \& Brown 2004).

\section{Background}

The Fresnillo mine is located in central Mexico within the State of Zacatecas (Figure 1). The mine lies on the Mexican Plateau, at the centre of the $800 \mathrm{~km}$ long silver belt, which runs NW-SE through Mexico. The mine is immediately south of the city of Fresnillo and approximately $53 \mathrm{~km}$ northwest of the city of Zacatecas, and $560 \mathrm{~km}$ northeast of Mexico City.

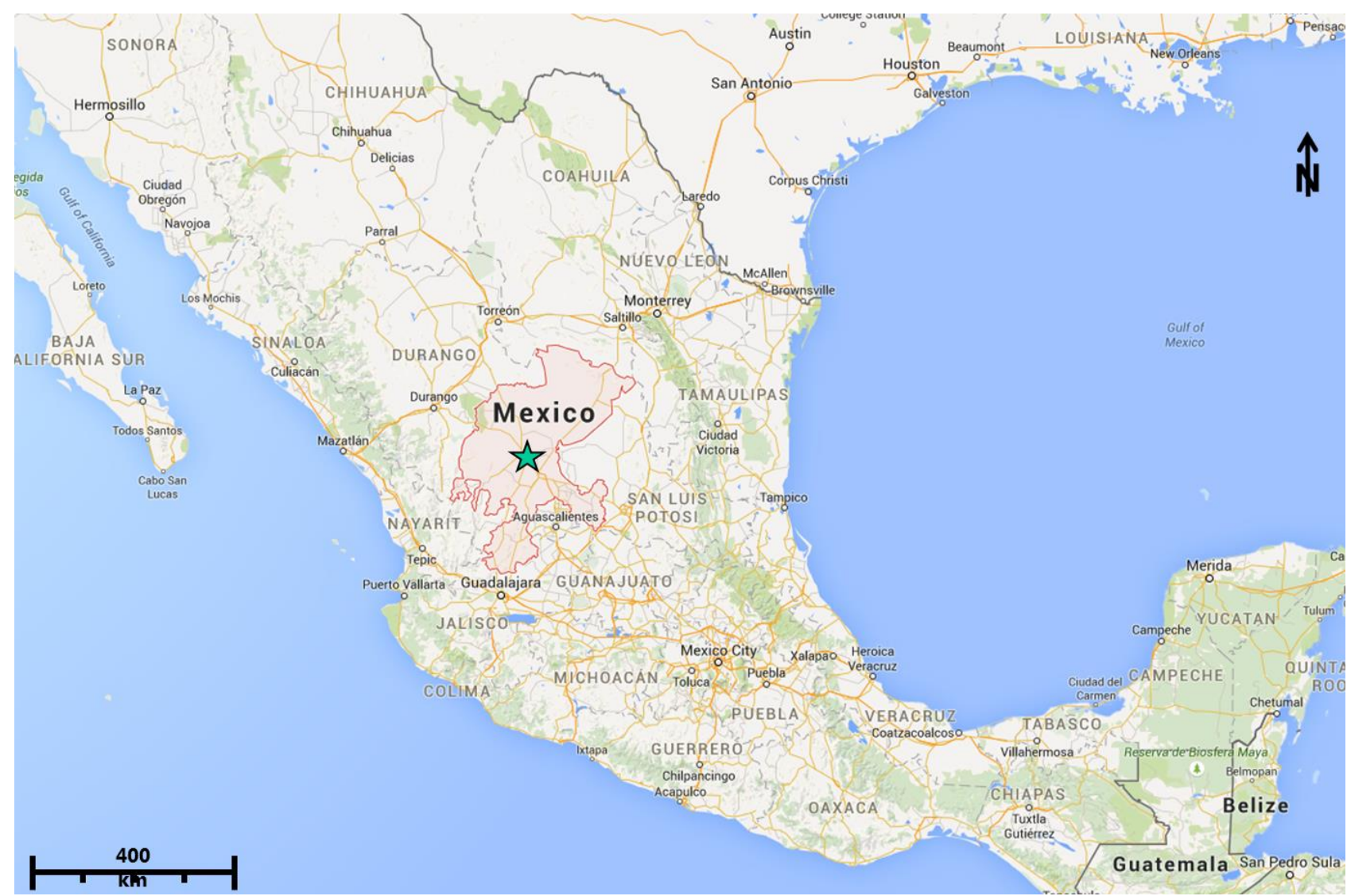

Figure 1 The Fresnillo mine location (green star) within the state of Zacatecas, Mexico (red shaded zone)

The underlying geology at Fresnillo is a Tertiary felsic volcanic rock overlying Cretaceous marine sediments and volcanics. Cretaceous to Jurassic sandstone, calcareous and carbonaceous shale, andesitic and felsic flow and pillow lava, marls and limestone form a thick sequence of deformed rocks. Several epithermal skarn deposits are hosted by deep northwest to southeast regional structural zones. A large magma related hydrothermal system produced the epithermal mineralisation.

The Fresnillo underground operations are currently accessed by three ramps to surface and two shafts. An extension of the San Carlos shaft is planned to reduce haulage costs and gain access to deeper ore reserves. The current shaft extends from surface to roughly $566 \mathrm{~m}$ below surface. The shaft expansion will extend the shaft an additional $440 \mathrm{~m}$ in depth to approximately $990 \mathrm{~m}$ below surface. The proposed construction footprint will be an $8.9 \times 2.8 \mathrm{~m}$ rectangular cross-section. The major ore handling infrastructure proposed at the bottom of the shaft consists of a truck dump station, run-of-mine and fine ore bins, crusher chamber, twin conveyor drifts and a loading pocket located approximately -925 to $-975 \mathrm{~m}$ below surface (Figure 2). 


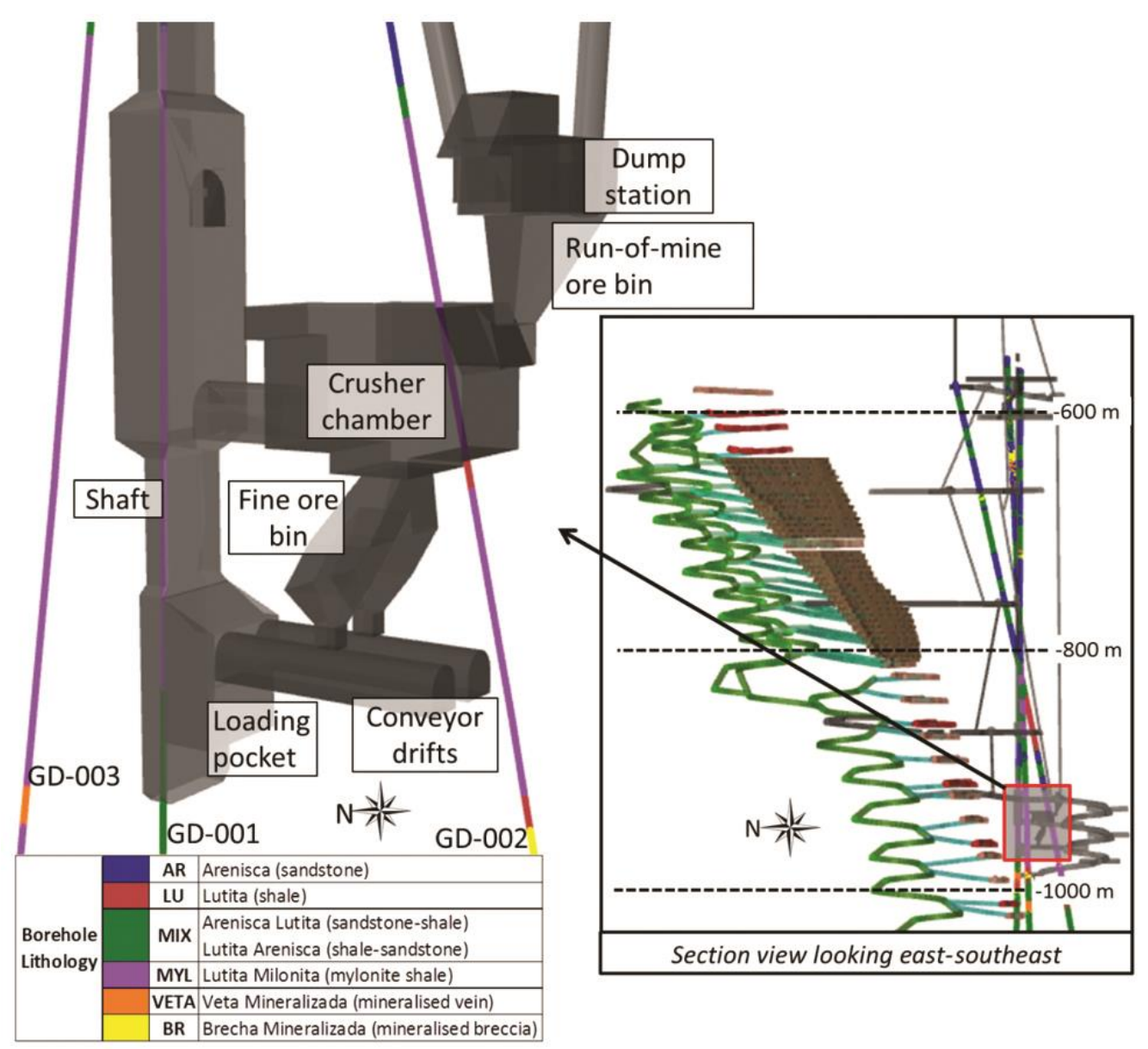

Figure 2 Proposed layout for permanent infrastructure at shaft bottom

\section{Geotechnical site investigation}

A geotechnical drilling program was conducted in 2015, including two 600 m orientated boreholes (GD-002 and GD-003) and one $500 \mathrm{~m}$ vertical borehole (GD-001) drilled in the vicinity of the proposed San Carlos Shaft Expansion. All boreholes were drilled to retrieve HQ3 core (61.1 mm diameter). Geotechnical core logging was conducted for the purpose of rock mass classification and the delineation of geotechnical domains. Orientated core was recovered from GD-002 and GD-003 for conventional structural logging and an acoustic televiewer survey was completed along the GD-001 borehole to retrieve additional structural orientations. An illustration of the orientation and location of the three boreholes is presented in Figure 3.

The units encountered within the boreholes consist primarily of sandstone, shale, or interbedded sandstone and shale units (mixed). The sandstone, shale and mixed units comprise $78 \%$ of the observed core. A mylonitic zone intersects the vertical borehole between 910 and $966 \mathrm{~m}$ below surface and accounts for $15 \%$ of all observed core. Minor intrusions of mineralised veins and mineralised breccia are also noted in the logged holes, and, combined, account for the remaining $7 \%$ of core length. The distribution of the rock units is shown in Figure 4. 

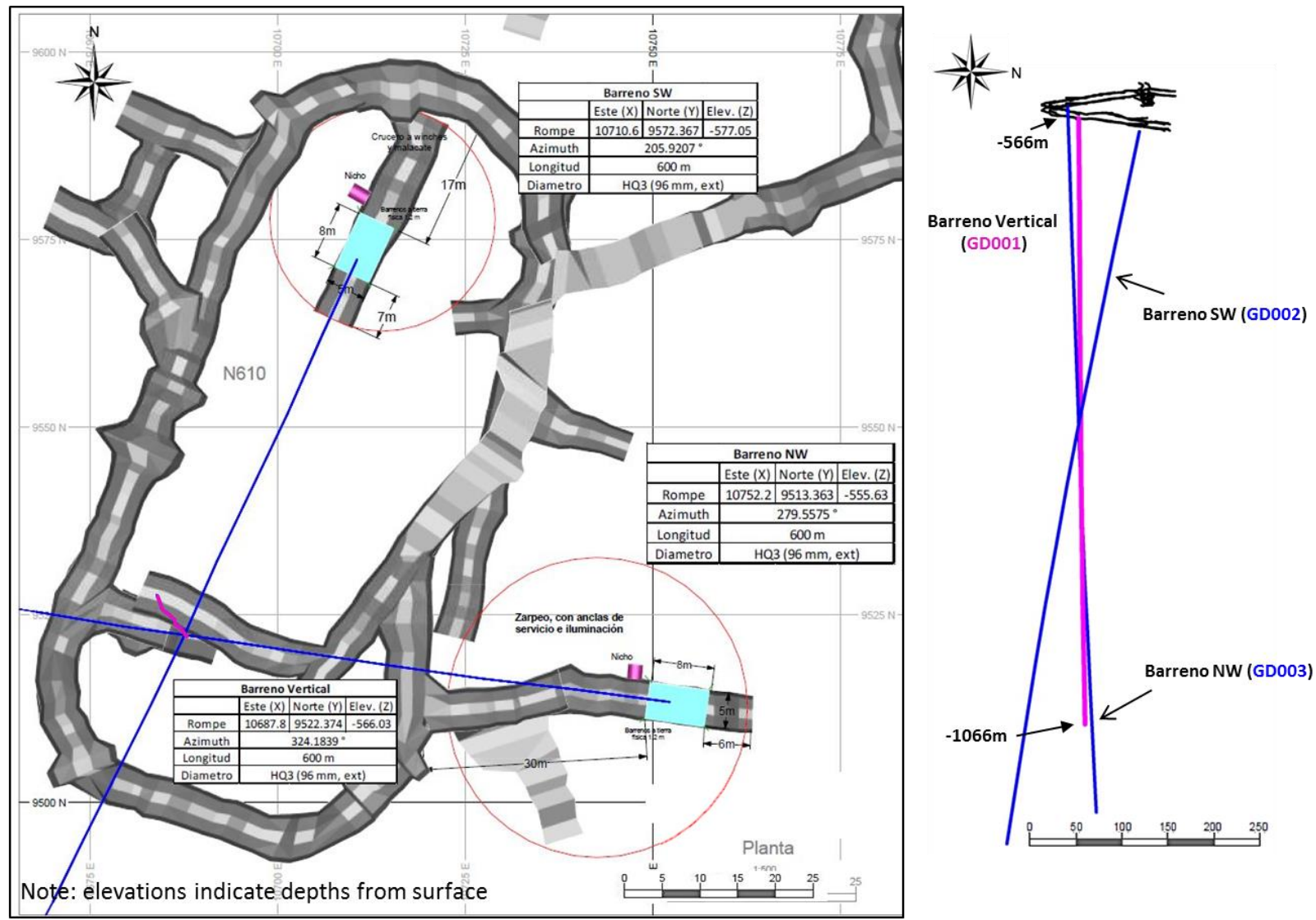

Figure 3 Orientation and location of the boreholes GD001, GD002 and GD003
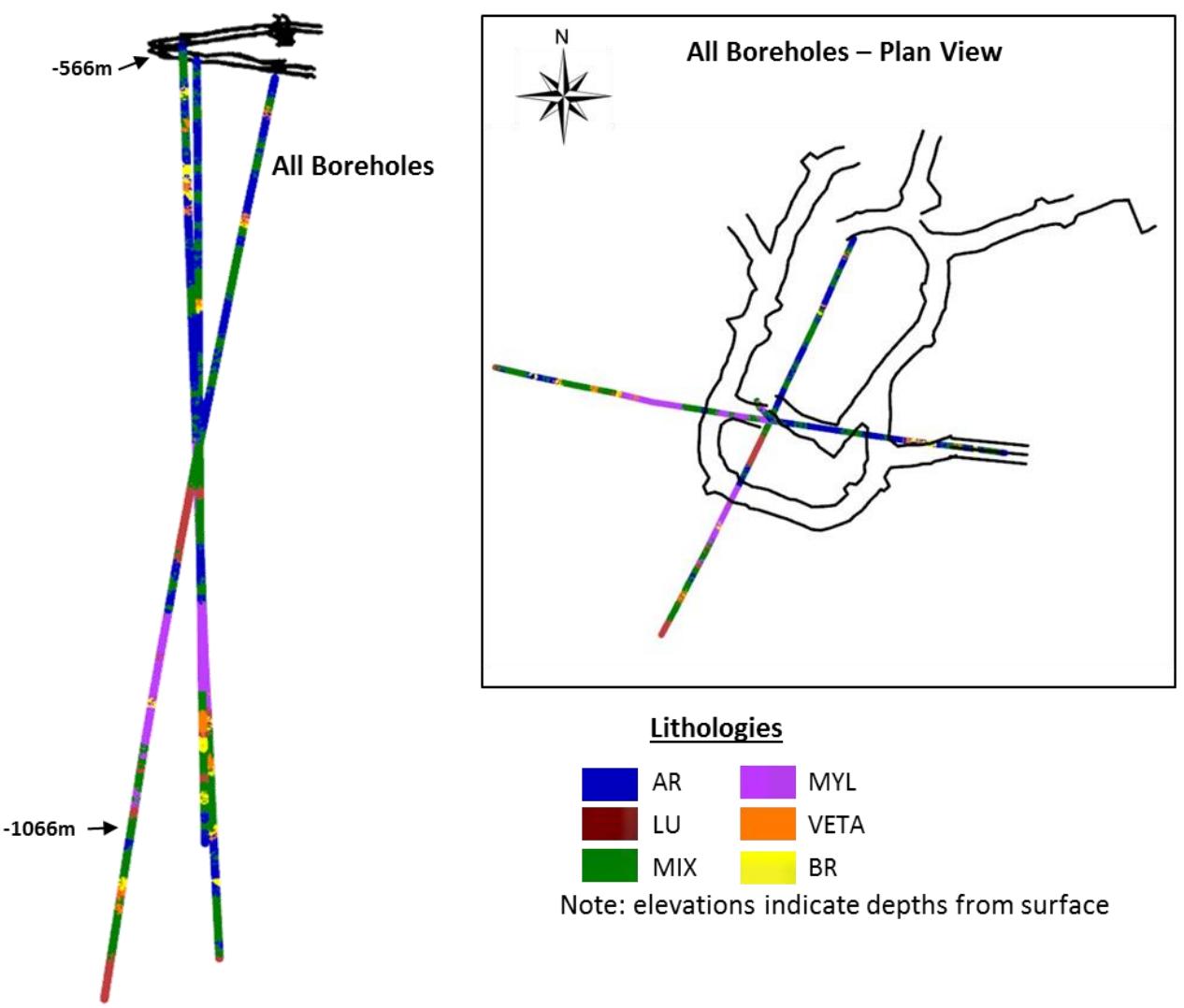

\section{Lithologies}

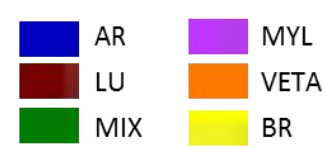

Note: elevations indicate depths from surface

Figure 4 Distribution of lithologies as used for the geotechnical analysis of the San Carlos Shaft 
In addition to geotechnical core logging, a laboratory testing campaign was conducted to determine intact material strength and elastic properties. A hydrogeological site investigation was also completed to evaluate dewatering requirements. The intact strength parameters and rock mass characterisation are summarised in Table 1. There is no data available at Fresnillo to quantify the in situ stress state. However, based on the tectonic setting it is generally assumed that the area is under gravitational loading (i.e. vertical stress is the weight of overlying rock, and horizontal stresses are $\leq 1.0$ times the vertical load).

Table 1 Summary of intact rock strength and rock mass characterisation by lithology

\begin{tabular}{lllll}
\hline Lithology & $\begin{array}{l}\text { Young's } \\
\text { modulus } \\
(\mathrm{GPa})\end{array}$ & $\begin{array}{l}\boldsymbol{\sigma}_{\mathrm{ci}} \\
(\mathrm{MPa})\end{array}$ & $\mathbf{Q}$ \\
\hline $\mathrm{AR}$ & Sandstone & 27.2 & 78.8 & $1.9-2.6$ \\
$\mathrm{LU}$ & Shale & 11.2 & 38.6 & $0.5-1.2$ \\
$\mathrm{MIX}$ & Sandstone-shale/shale-sandstone & 22.1 & - & $1.3-1.9$ \\
$\mathrm{MYL}$ & Mylonite shale & 9.7 & 48.5 & $0.7-1.4$ \\
$\mathrm{BR}$ & Mineralised breccia & 19.7 & 55.7 & - \\
\hline
\end{tabular}

\section{$4 \quad$ Preliminary design considerations within the mylonite shale}

Geotechnical design of the shaft expansion utilised empirical and numerical methods to estimate ground response during construction and over the life-of-mine, and evaluate ground support needs accordingly.

\subsection{Numerical methods}

Multiple numerical approaches at varying scales where utilised to evaluate ground reaction to construction and mining. Two- and three-dimensional modelling was utilised to evaluate the ground response during shaft sinking. Three-dimensional numerical modelling was utilised to assess the stability of the bottom infrastructure during construction. Three-dimensional simulations were also used to evaluate the influence that mine-induced stress changes during ore extraction may have on the excavation stability and inferred support performance over the life-of-mine. The properties for this numerical simulation of ground behaviour in and around shaft bottom are based on the mylonite shale (MYL) rock mass. The constitutive model for plastic analysis uses perfectly plastic Hoek-Brown failure criterion with a non-associated flow rule and zero dilation. This simplified approach was appropriate as no data was available to quantify plastic ground response to mining at the time of the study, and calibration of the numerical model was not possible.

The base case far field in situ stress conditions were assumed to be an extensional tectonic zone $\left(\mathrm{K}_{\mathrm{o}}=0.5\right.$; $\sigma_{2}=\sigma_{3}$ ). In the absence of model calibration, sensitivity testing was completed to evaluate the influence of a more conservative $\mathrm{K}$ ratio ( $\mathrm{K}_{\mathrm{o}}=1$; resulting in elevated far field horizontal stress magnitudes).

\subsection{Empirical methods}

Empirical assessments were also employed to provide additional sustenance to ground support design. Grimstad and Barton (1993) guidelines relate the intended use of an excavation and its span to the rock mass quality (using the $Q$ rock mass classification system), and these guidelines were considered. The planned shaft bottom development at the Fresnillo mine will be sited approximately $950 \mathrm{~m}$ below surface within the MYL unit. Using the knowledge of rock strength available for the MYL unit during preliminary design, it was expected that the openings may experience some form of squeezing ground conditions. Potvin and Hadjigeorgiou (2008) discuss the necessary conditions for squeezing in mining environments, and common to all mines is the presence of a prominent structural feature. A high stress field, relative to rock strength, is also necessary, and squeezing is most dominant in cases where the host rock is weak (unconfined 
compressive strength (UCS) <60 MPa). The Fresnillo ore handling excavations are hosted in MYL unit, which is considered to be massive, however, fails readily along thinly spaced graphitic seams. These graphitic seams were deemed susceptible to bucking failure (Figure 5). The degree of expected squeezing is dependent on the thickness of the foliation layers present (Potvin \& Hadjigeorgiou 2008). The risk of squeezing is greatest where foliation is near parallel to excavation faces.

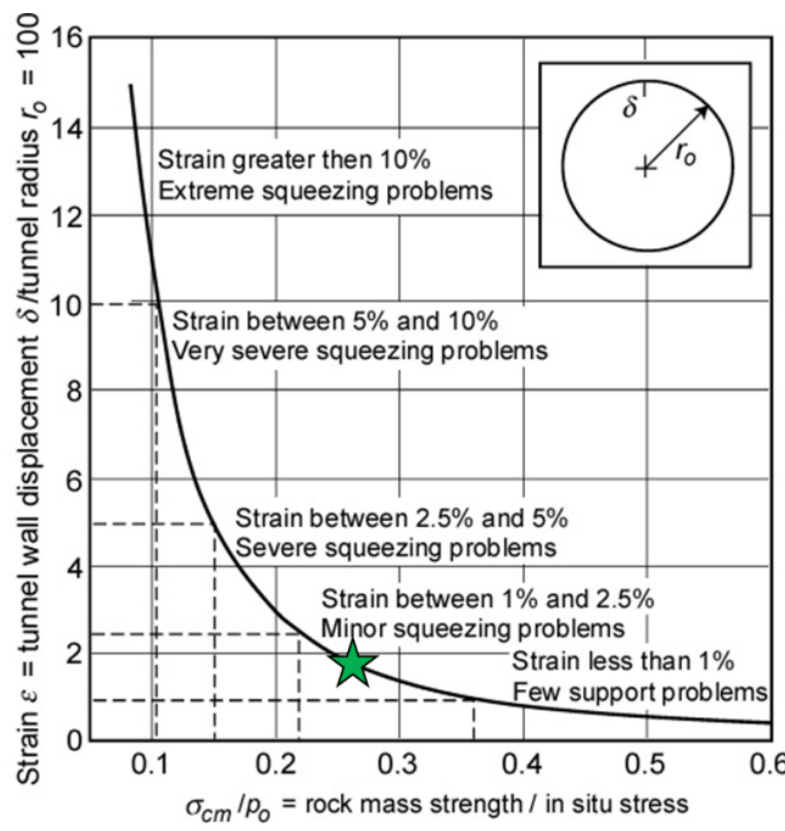

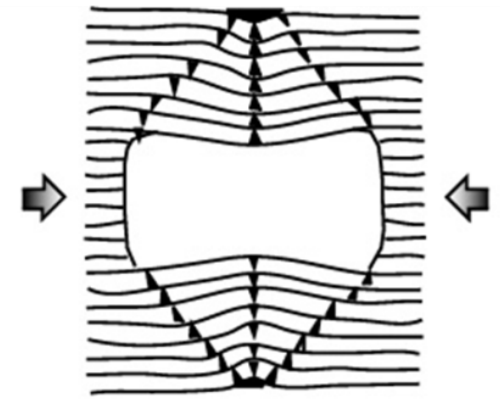

b) Buckling failure

Figure 5 Empirical estimate of squeezing: (left) plot after Hoek (2001); and, (right) buckling failure mechanism in squeezing ground after Potvin and Hadjigeorgiou (2008)

With knowledge of this susceptibility to squeezing, and the support design estimates made by empirical approximations, preliminary support design was completed. The empirical support design recommendations were further refined using analytical and numerical techniques to determine adequacy in stabilising any structurally controlled instability, and against any potential squeezing ground conditions during initial construction of the shaft and shaft bottom infrastructure.

\subsection{Preliminary design outcomes}

One of the most significant risks identified during preliminary design was that deep yield (relative to the excavations' dimensions) was expected in the very poor quality rock mass, and that the rock mass may be susceptible to squeezing, particularly in the large ore handling infrastructure excavations. Stiff ground elements (such as fully grouted rebar and shotcrete) are not able to accommodate large deformation. However, stiff support can provide some resistance to deformation. Screens would tend to bag up under the anticipated conditions, and this would be extremely difficult to rehabilitate during mine operations. 


\subsubsection{Shaft support}

The timing of support installation in the shaft (i.e. lag time behind the face) was defined by the anticipated ground reaction so that the strain demand on bolts and the shaft liner would not exceed their capacity. Cable bolts were required in the design to provide deep anchor in solid ground along the long $8.9 \mathrm{~m}$ axis of the shaft (with only $2.8 \mathrm{~m}$ available for installation). A comprehensive instrumentation program was designed as a means to quantify ground reaction during construction and monitor ground support loading over the operational life of this critical mine infrastructure. Deformations measured during construction of the shaft will be critical for quantitative calibration of numerical models. Early deformations are expected to equilibrate once construction is completed (stabilisation of the ground reaction curve).

\subsubsection{Crusher station and ore handling excavations support}

It was deemed necessary to apply a sacrificial layer of fibrecrete in-cycle during development of the large excavations near the shaft bottom, with screen and bolts applied over the fibrecrete. While the fibrecrete is likely to crack and break up, it will act to contain finely broken rock. Bolts and screen over the fibrecrete will provide containment. D-bolts were selected for their high strength (20-25 tonnes) and large deformation capacity (15\%); fully encapsulated bolts were deemed necessary to mitigate exposure to corrosion in the life-of-mine infrastructure.

Borehole extensometers are to be installed at the same time as first pass bolting and these instruments are to be read on a frequent basis (each shift). Once deformations stabilise, a final layer of fibrecrete will be applied over the screen and bolts. During preliminary design, it is impossible to predict the total deformation, or how long it will take for deformations to stabilise. Monitoring is considered important to verify design adequacy during construction.

Consideration was also given to later stress loading induced by orebody extraction that could drive a second phase of rock mass strain if the critical infrastructure is within the zone of stress redistribution. As orebody extraction advances towards the shaft pillar, it will be possible to observe any re-activation of rock mass strain using the same instruments installed during initial construction; if mine induced stresses are imposed on the shaft pillar. Shaft pillar dimensioning was evaluated in order to set extraction limits on ore recovery in order to mitigate mine-induced stress loading on the shaft infrastructure.

\section{Observation of mylonite shale performance}

Several months after preliminary geotechnical design, for the shaft and shaft bottom, infrastructure had been completed, however, still prior to shaft construction, the MYL unit was intersected at various locations ranging from 610 to $790 \mathrm{~m}$ below surface. A site inspection was completed to evaluate performance of the MYL, with particular interest at the deepest occurrences. Underground exposure of the MYL (Figure 6) confirmed the rock mass characterisation from geotechnical core logging. The MYL unit was verified to be a massive (sparsely jointed) weak rock, with upper bound UCS estimated to be $50 \mathrm{MPa}$, but can be as low as $20 \mathrm{MPa}$. Pervasive graphitic alteration within this unit contributes to the very low intact strength, with the intact rock easily fractured on weak graphitic seams. 


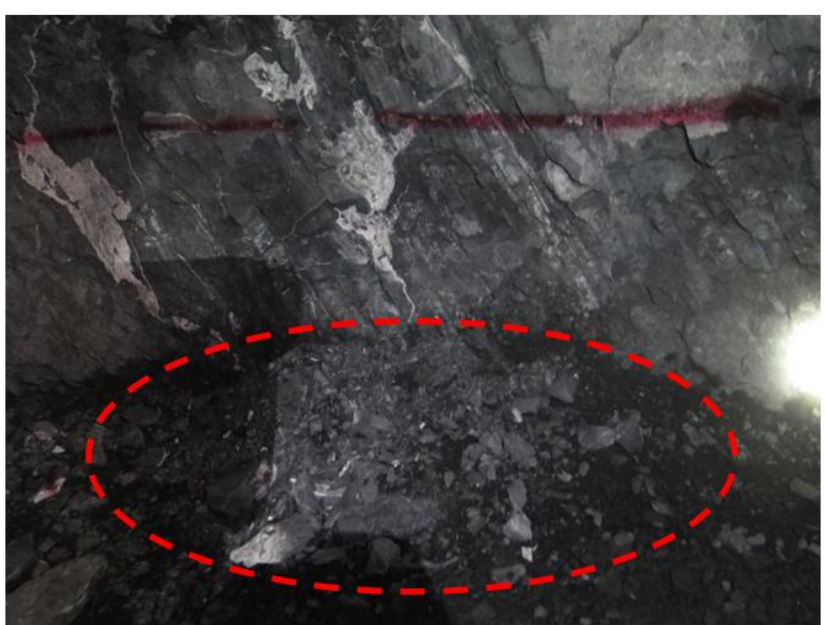

Accumulation of 'chips' along wall showing accumulation of stress damage in ribs.

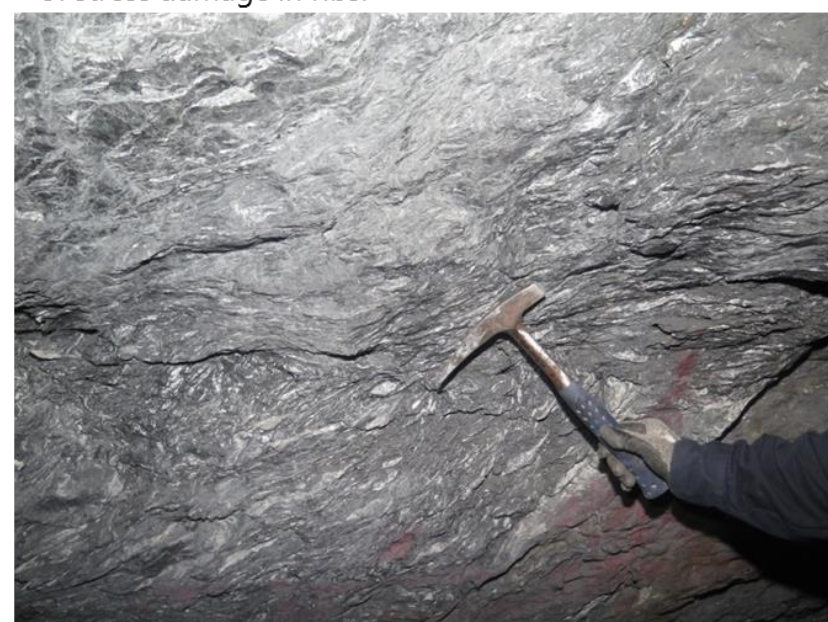

MYL fabric

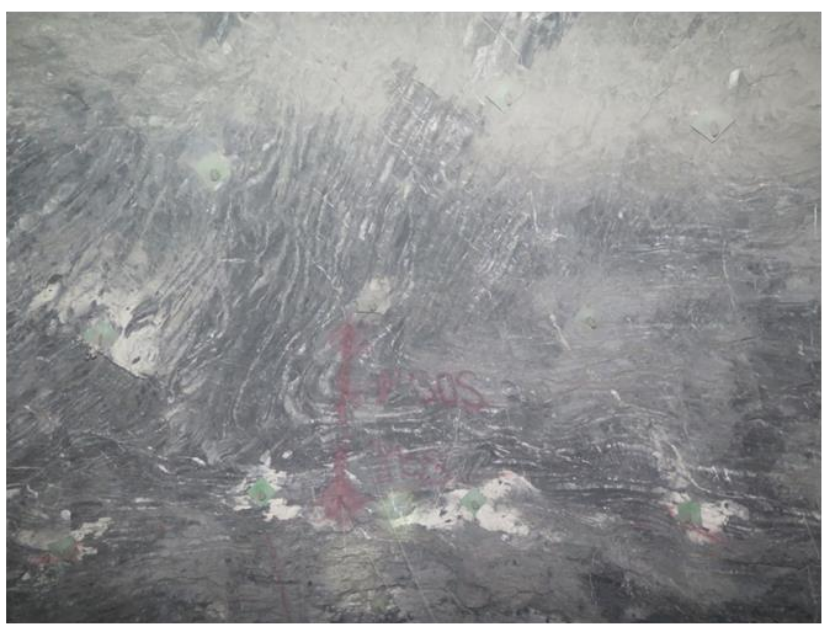

Folding of bedding observed in the back.

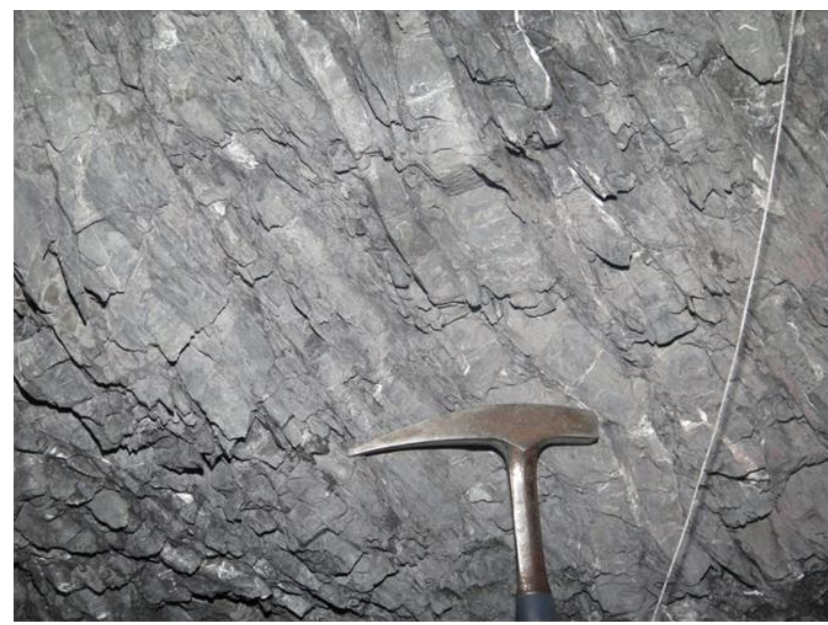

Friable fabric enhanced by stress damage in ribs

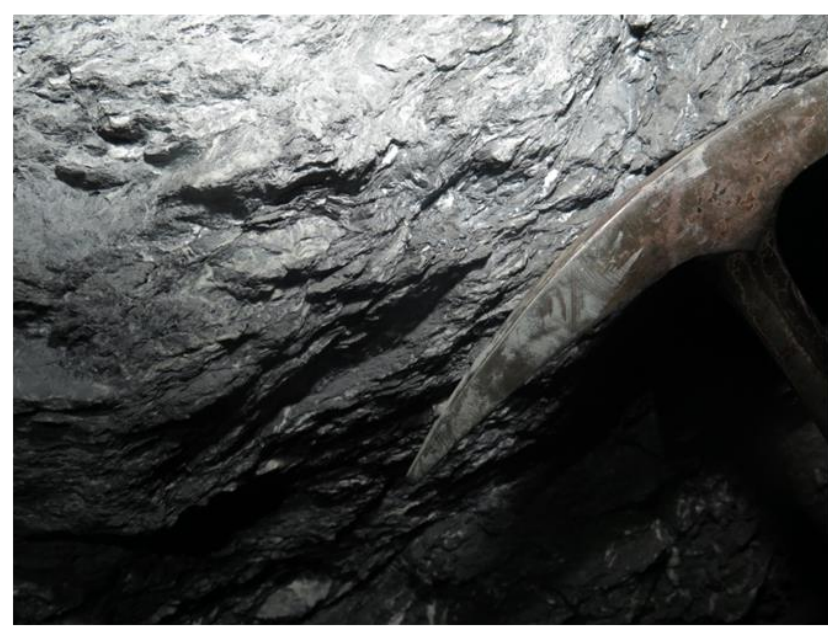

MYL fabric

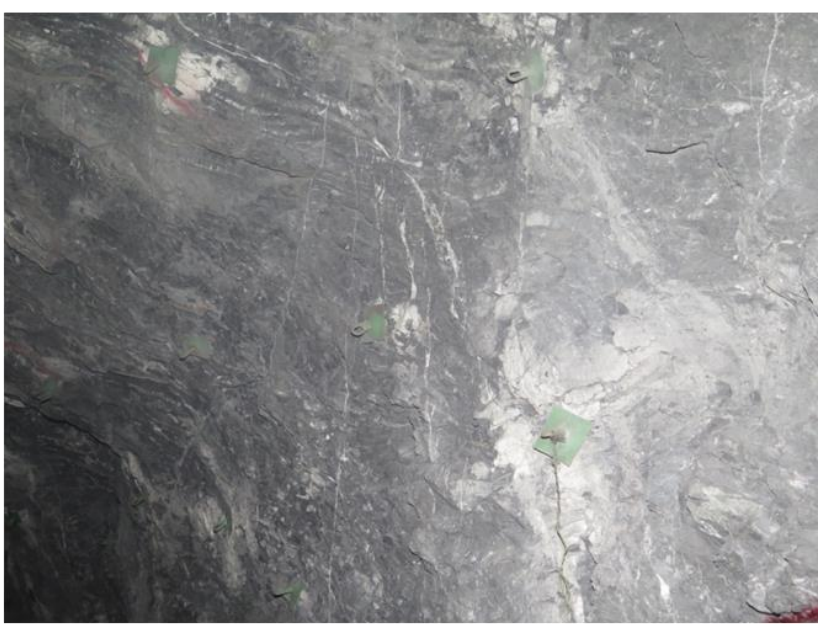

Back and shoulder in good condition with pattern bolting.

\section{Figure 6 Underground exposures of mylonite shale unit}

From the assumed in situ stress state, the estimated major principal stress by depth in the areas observed are summarised in Table 2 . The onset of stress induced damage in a rock mass will typically occur when the major principal stress is near $30-50 \%$ of the UCS. Heavy stress induced damage (for example squeezing or rockbursting) can be anticipated where the major principal stress is near $60 \%$ of the UCS. By these general 
estimates, assuming a gravitational stress field, visible signs of the onset of stress induced damage would be anticipated in the MYL at depths in the order of 500 to $600 \mathrm{~m}$, and observable damage would be certain near depths of 700 to $800 \mathrm{~m}$.

Table 2 Estimates of gravitational stress loading by depth

\begin{tabular}{lll}
\hline Depth $(\mathrm{m})$ & $\boldsymbol{\sigma}_{\mathrm{v}}(\mathrm{MPa})$ & $\boldsymbol{\sigma}_{\mathrm{v}} /$ UCS (as \% for UCS = 25 to $\mathbf{5 0} \mathbf{~ M P a}$ ) \\
\hline 400 & 11 & 22 to $43 \%$ \\
\hline 450 & 12 & 24 to $49 \%$ \\
\hline 500 & 14 & 27 to $54 \%$ \\
\hline 550 & 15 & 30 to $59 \%$ \\
\hline 600 & 16 & 32 to $65 \%$ \\
\hline 650 & 18 & 35 to $70 \%$ \\
\hline 700 & 19 & 38 to $76 \%$ \\
750 & 20 & 41 to $81 \%$ \\
800 & 22 & 43 to $86 \%$ \\
\hline
\end{tabular}

Observations of the MYL unit from this visit concluded that drift-scale excavations perform well to depths of $790 \mathrm{~m}$, with only minor stress damage observed in the walls. It is noted that development in MYL at depth is relatively new and long-term performance was not observed. This observation suggests that the stress magnitudes are lower than would be expected under gravitational loading and it was proposed that the lower than expected stress magnitudes may be due to the redistribution of stress from the soft, weak MYL to stiffer and stronger adjacent units, for example the sandstone.

\section{Back-analysis of observed conditions}

In order to follow up on the observation of the MYL unit performing well to depths of $790 \mathrm{~m}$, numerical back-analyses of drift development in the MYL has been completed in order to better estimate the local in situ stresses. The numerical evaluation aimed to evaluate how variable k-ratios influenced drift stability and to test the concept that stress magnitudes are lower than would be expected under gravitational loading. The numerical analysis utilised the Hoek-Brown failure criteria for MYL; $\sigma_{c i}=48.5 \mathrm{MPa}, \mathrm{m}_{\mathrm{b}}=2.02, \mathrm{~s}=0.012$, $\mathrm{a}=0.5$. Far field stress conditions were systematically adjusted so that numerically predicted damage around the drift excavation is similar to observations made underground.

Assuming a gravitational stress field, the vertical stress should be in the order of $20 \mathrm{MPa}$. The horizontal stress magnitudes are assumed to be roughly 0.5 to 1.0 times the vertical load. Using these values in a numerical stress analysis produces extensive shear and tensile damage in the back (Figure 7; $\sigma_{v}=20 \mathrm{MPa}$, $\sigma_{\mathrm{h}}=20 \mathrm{MPa}$ and $\sigma_{\mathrm{v}}=20 \mathrm{MPa}, \sigma_{\mathrm{h}}=10 \mathrm{MPa}$ ). This damage was not observed underground. By reducing the vertical load, while maintaining a $\mathrm{k}$ ratio of 1.0, the depth of damage is reduced, however, damage across the back is not eliminated. Numerical model results suggest that the far field stresses in the MYL must be significantly less than would be expected by homogeneous gravitational loading and that the $k$ ratio must be 0.5 or less. By back-analysis, the major principal stress in the MYL at $790 \mathrm{~m}$ depth is estimated to be vertical and in the order of 10 to $15 \mathrm{MPa}$, and the horizontal stresses are in the order of $5 \mathrm{MPa}$. This is illustrated in Figure 7 where the drift back is stable and some damage occurs in the drift side walls. 


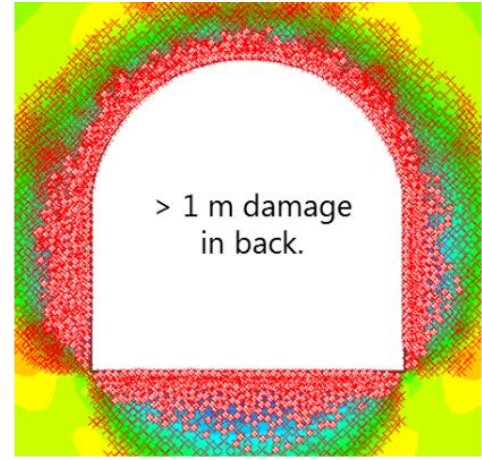

$\sigma_{\mathrm{v}}=20 \mathrm{MPa}, \sigma_{\mathrm{h}}=20 \mathrm{MPa}$

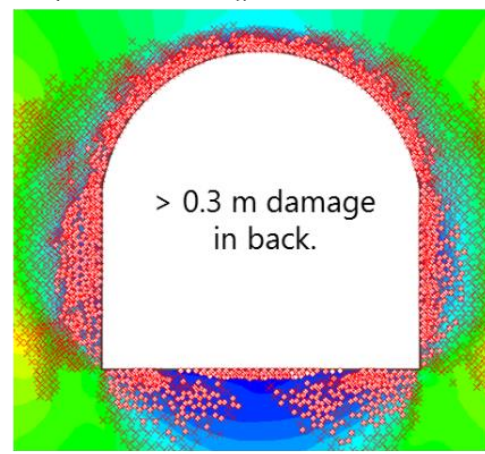

$\sigma_{\mathrm{v}}=20 \mathrm{MPa}, \sigma_{\mathrm{h}}=10 \mathrm{MPa}$

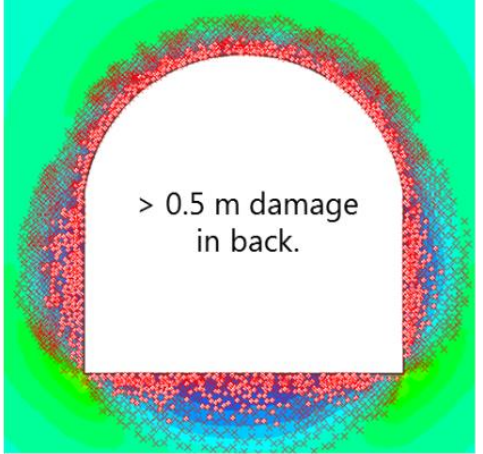

$\sigma_{\mathrm{v}}=10 \mathrm{MPa}, \sigma_{\mathrm{h}}=10 \mathrm{MPa}$

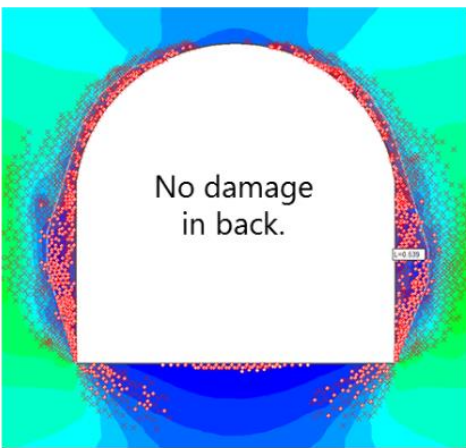

$\sigma_{\mathrm{v}}=10 \mathrm{MPa}, \sigma_{\mathrm{h}}=5 \mathrm{MPa}$

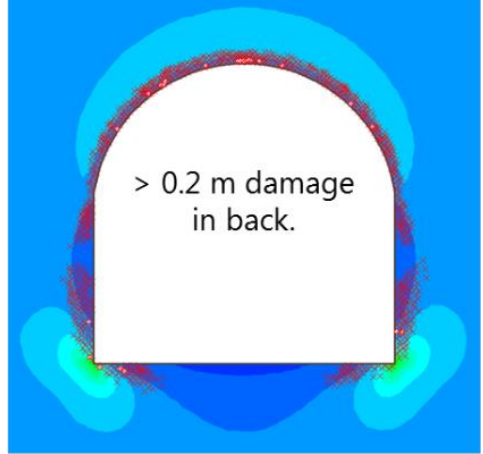

$\sigma_{\mathrm{v}}=5 \mathrm{MPa}, \sigma_{\mathrm{h}}=5 \mathrm{MPa}$

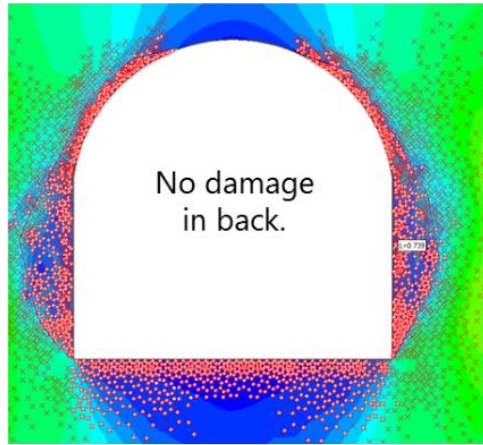

$\sigma_{\mathrm{v}}=15 \mathrm{MPa}, \sigma_{\mathrm{h}}=5 \mathrm{MPa}$

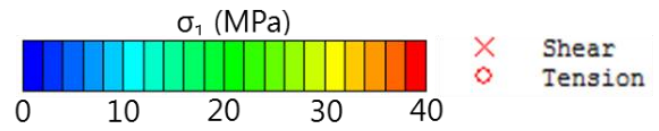

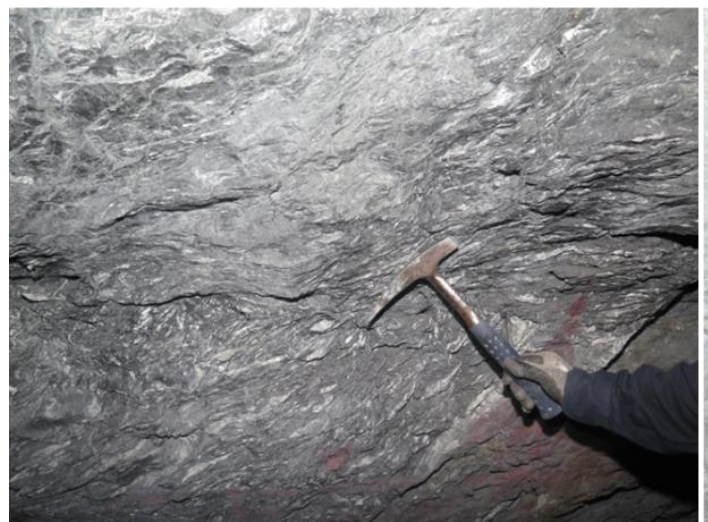

The MYL fabric (left) was visibly enhanced in the drift sidewalls as an artifact of accumulated stress damage.

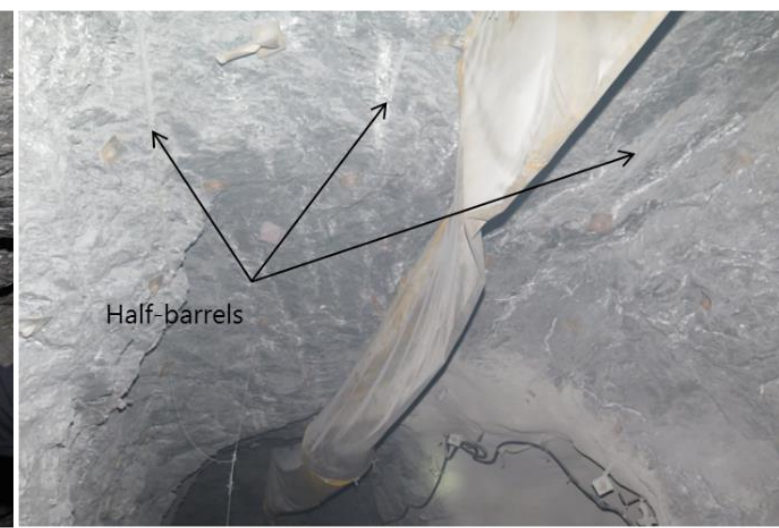

No visible damage in back.

Figure 7 Back-analysis of observed mylonite shale performance

It was hypothesised that the lower than expected stress magnitudes may be the result of stress redistribution between lithological units with contrasting stiffness. The elastic modulus of the MYL is much lower than the elastic modulus for the sandstone $(A R)\left(E_{M Y L}<<E_{A R}\right)$. This condition is illustrated by the examples provided in Figure 8 and a more sophisticated three-dimensional model shown in Figure 9. This assessment demonstrates that the anomalous stress conditions are controlled by the physical response of multiple geological units to gravitational loading. A three-dimensional geological model defining major lithological units in the lower part of the mine is exceptionally important in order to refine the numerical modelling, which is necessary to better estimate the anticipated distribution of in situ stress throughout the mine. In the absence of a geological model to define the approximate boundaries between major lithological units it is nearly impossible to estimate how the in situ stresses may vary spatially. 


$$
\sigma=\frac{E}{\varepsilon} \quad\left\{\begin{array}{l}
\sigma=\text { stress } \\
\varepsilon=\text { strain } \\
E=\text { Modulus of elasticity (stiffness) }
\end{array}\right.
$$

Gravitational load

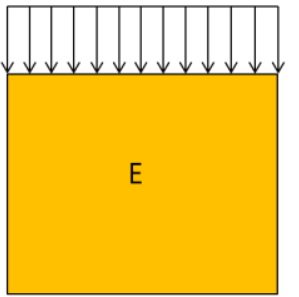

For a homogeneous material the stiffness $(E)$ is constant and so the stress $(\sigma)$ is also constant for a distributed load.

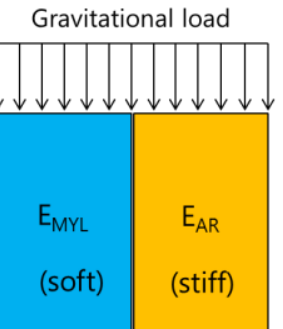

For heterogeneous conditions $\left(E_{M Y L}<E_{A R}\right)$ under uniform loading it may be assumed that the induced strain is similar for all units $\left(\varepsilon_{\mathrm{MYL}}=\varepsilon_{\mathrm{AR}}\right)$.

The resulting stresses are not equal $\left(\sigma_{M Y L}<\sigma_{A R}\right)$

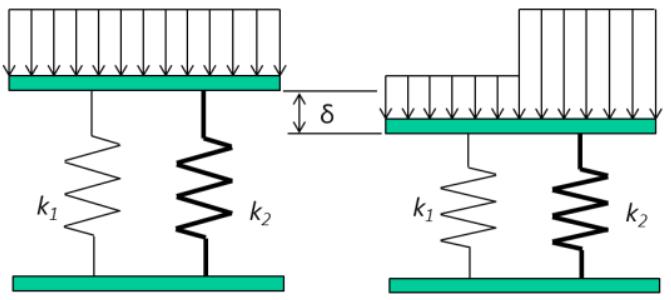

These mechanics are also

represented by a spring model

where the force in a spring $(F)$ is

equal to the spring stiffness $(k)$

multiplied by the imposed

deformation $(\delta)$$$
F=\delta k
$$

if $k_{1}<k_{2}$ then $F_{1}<F_{2}$

\section{Figure 8 Effect of varying rock mass stiffness}

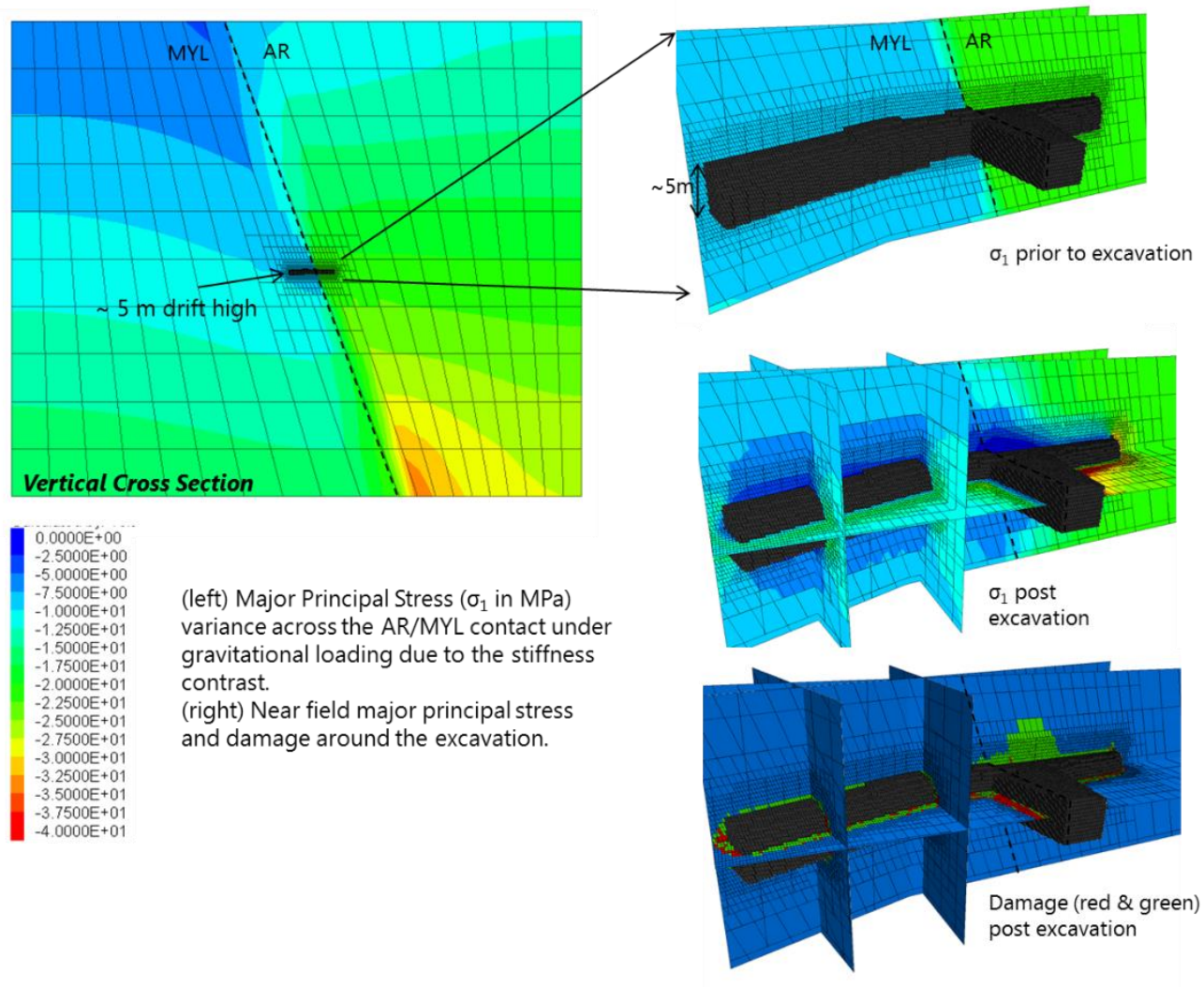

Figure 9 Back-analysis of observed mylonite shale performance 


\section{Implications to shaft and shaft bottom infrastructure design}

Some portions of the shaft expansion and the shaft bottom ore handling infrastructure are expected to be excavated in the MYL. To further evaluate excavation stability, support requirements and geomechanical risk during construction, and while stopes in the area are mined, it is necessary to refine the anticipated in situ stress conditions by numerical methods once the geological model is available.

Stress shedding from soft to stiff rock units has the following implications to engineering design:

- Ground reaction predictions are overly conservative in the weak, soft units. This would result in overly conservative ground support design and may have significant financial implications to development in these units at depth (excess ground support cost and the associated implications to development rates and scheduling).

- Stress conditions in the stiffer, more competent units may be underestimated. This may contribute added risk when developing in these units at depth, as the adverse implications of excess stress (strainbursting, rockbursting) are not accounted for in design and are not anticipated by operations.

\section{Conclusion}

Geotechnical designs are commonly data limited with considerable uncertainty in geotechnical design parameters. These inherent uncertainties contribute to elevated geotechnical risk. Data uncertainty and associated risks can be mitigated by the continuous and targeted observation of ground response and associated performance of designs as mining progresses and the information becomes available. These observations are used to enhance the understanding of the geomechanical model and optimise the design strategy for future mining. In this case study, this enhancement was accomplished through the back-analysis of the observed ground behaviour, in order to refine inputs to the numerical model. In an operating mine, this process becomes increasingly important as the extraction ratio increases and the redistribution of stresses becomes more complex.

\section{Acknowledgement}

The engineering team at Mine Design Engineering (MDEng) would like to thank Fresnillo Plc. for permission to publish this case study.

\section{References}

Bawden, WF 2015, 'The expanding impact of technology on underground geomechanical mine design and operations - advances, limitations and future needs', in Y Potvin (ed.), Proceedings of the International Seminar on Design Methods in Underground Mining, Australian Centre for Geomechanics, Perth, pp. 3-20.

Brady, BHG \& Brown, ET 2004, Rock Mechanics: For Underground Mining, Kluwer Academic Publishers, Dordrecht, The Netherlands. Grimstad, E \& Barton, N 1993, 'Updating the Q-System for NMT', in C Kompen, SL Opsahl \& SL Berg (eds), Proceedings of the International Symposium on Sprayed Concrete - Modern Use of Wet Mix Sprayed Concrete for Underground Support, Norwegian Concrete Association, Oslo.

Hadjigeorgiou, J 2012, 'Where do the data come from?', in Y Potvin (ed.), Proceedings of the Sixth International Seminar on Deep and High Stress Mining, Australian Centre for Geomechanics, Perth, pp. 259-277.

Hoek, E 2001, 'Big tunnels in bad rock', ASCE Journal of Geotechnical and Geoenvironmental Engineering, vol. 127, no. 9, pp. 726-740.

Holling, CS 1978, Adaptive Environmental Assessment and Management, John Wiley \& Sons, Chichester, UK, abstract can be viewed at http://pure.iiasa.ac.at/823/

Potvin, Y \& Hadjigeorgiou, J 2008, 'Ground support strategies to control large deformations in mining excavations', in TR Stacey \& D Malan (eds), Proceedings of The 6th International Symposium on Ground Support in Mining and Civil Engineering Construction, The Southern African Institute of Mining and Metallurgy, Johannesburg, pp. 545-560. 